\title{
Erratum to: An Efficient Clustering Technique for Unstructured Data Utilizing Latent Semantic Analysis
}

\author{
Yonghoon Kim and Mokdong Chung ${ }^{(\bowtie)}$ \\ Department of Computer Engineering, Pukyong National University, \\ 45 Yongso-ro, Nam-gu, Busan, Korea \\ kimyhjava@pukyong.ac.kr, mdchung@pknu.ac.kr
}

\section{Erratum to:}

Chapter "An Efficient Clustering Technique for Unstructured Data Utilizing Latent Semantic Analysis" in:

J. J. Park et al. (eds.), Advances in Computer Science

and Ubiquitous Computing, Lecture Notes in Electrical

Engineering 474,

https://doi.org/10.1007/978-981-10-7605-3_38

In the original version of the book, the following belated corrections have been incorporated in chapter "An Efficient Clustering Technique for Unstructured Data Utilizing Latent Semantic Analysis":

Email id "mdcung@pknu.ac.kr" of the second author "Mokdong Chung" has been changed as "mdchung@pknu.ac.kr".

"Acknowledgements" has been deleted.

The updated online version of this chapter can be found at https://doi.org/10.1007/978-981-10-7605-3_38 